\title{
Pengaruh Perhatian Orang Tua dan Peran Guru Terhadap Motivasi Belajar Siswa Masa Pandemi Covid-19
}

\author{
Ary Prasetyo \\ Program Studi Manajemen Sekolah Tinggi Ilmu Ekonomi Galileo, arypras22@gmail.com
}

Sukarni

Program Studi Pendidikan Agama Islam STAI Ibnu Sina Batam, karniprasetyo86@gmail.com

\begin{abstract}
Abstrak
Penelitian ini bertujuan untuk menguji dan menganalisis pengaruh variabel eksogen: perhatian orang tua dan peran guru terhadap variabel endogen: motivasi belajar siswa semasa pandemik Covid-19 di Sekolah Dasar Islam Assakinah Batam. Model penelitian ini termasuk dalam jenis penelitian lapangan dengan menggunakan metode penelitian kuantitatif dan instrumen yang digunakan dalam penelitian ini adalah kuesioner. Teknik pengumpulan data menggunakan teknik simple random sampling dengan sampel sebanyak 190 siswa dari populasi 360 siswa. Teknik analisis dalam penelitian ini menggunakan metode structural equation model (SEM). Hasil dari penelitian ini perhatian orang tua $\left(X_{1}\right)$ berpengaruh secara positif dan signifikan terhadap motivasi belajar siswa $(Y)$ dan juga peran guru $\left(X_{2}\right)$ berpengaruh secara positif dan signifikan terhadap motivasi belajar siswa (Y) semasa pandemik Covid-19 di Sekolah Dasar Islam Assakinah Batam.
\end{abstract}

Kata Kunci ditulis: Perhatian orang tua, peran guru, motivasi belajar

\section{PENDAHULUAN}

Pada Akhir Januari 2020 World Health Organization atau disingkat WHO menetapkan keadaan darurat karena adannya penyakit jenis baru yaitu Coronavirus Diseases 2019 (Covid19), yang menjadi sebuah persoalan global yang dihadapi dunia tidak terkecuali di bidang pendidikan. Pada Era pandemik ini mewajibkan sekolah untuk mengubah sistem atau metode pembelajaran tatap muka dengan pembelajaran dalam jaringan atau daring, sehingga guru dituntut menyediakan materi pembelajaran dan mengajar siswa melalui daring atau alat digital jarak jauh. (Fitriyani, Fauzi, \& Sari, 2020). Pemerintah dalam hal ini Menteri Pendidikan dan kebudayaan Republik Indonesia menghimbau pada daerah yang terdampak pandemik Covid-19 atau virus corona, untuk menghentian sementara kegiatan belajar tatap muka di sekolah dan mengajak para guru mengajar dengan menggunakan teknologi atau secara daring (Purwanto et. al., 2020).
Pada saat pademik Covid-19 banyak orang tua mengalami stres khususnya terkait dengan peran mereka sebagai orang tua, Ketika menyangkut anak-anak mereka, kekhawatiran tentang masalah perilaku atau kesehatan, kesulitan pendidikan, dan bahkan tugas seharihari (Griffith, 2020). Beberapa orang tua menghadapi beban tuntutan yang meningkat dari proses pembelajaran during anak-anak, sementara mereka masih berusaha untuk melakukan pekerjaan ditempat kerja (Coyne et. al., 2020). Selama berada dirumah anak-anak juga merasa frustasi karena semua kegiatan mereka dilakukan dirumah saja dan pemindahan kelas tatap muka disekolah dengan pembelajaran during membuat anak kurang pengawasan pada saat pembelajaran berlangsung, terutama saat orang tua mereka bekerja (Pan, Cui, \& Qian, 2020). Dukungan dan tanggung jawab orang tua menunjukkan peranyang signifikan saat anak-anak mereka berpartisipasi dalam pendidikan during sehingga dapat memotivasi anak untuk mencapai 
keberhasilan dalam pembelajaran during (Garbe et. al., 2020).

Perhatian orang tua dan peran Guru mempunyai peranan penting untuk memotivasi atau memberikan dukungan sosial di daalm rumah supaya anaknya tersebut nyaman dalam belajar, akan tetapi Komisi Perlindungan Anak Indonesia (KPAI) menerima sejumlah keluhan dari orang tua siswa bahwa anaknya stres karena berbagai tugas guru selama program pembelajaran during (Pajarianto et. al., 2020).

Perhatian orang tua sangat penting untuk membimbing agar anak-anak dapat melakukan semua tugas dan kewajiban untuk membentuk kepribadian anak. Perhatian orang tua dalam hal pendidikan dengan memberikan motivasi, bimbingan, saran, observasi proses belajar, penghargaan dan pemenuhan kebutuhan anak akan memudah anak dalam mengembangakan potensinya (Tellu, Kadir \& Kasim, 2017). Guna mencapai tujuan dari satu pendidikan diperlukan suatu proses atau sistem pembelajaran, baik pembelajaran di sekolah, dimasyarakat dan pembelajaran di rumah (keluarga). Pengorganisasian pembelajaran selain guru disekolah, peran orang tua di rumah (keluarga) juga sangat penting dalam meningkatkan hasil belajar yang baik (Ambarwati, 2018). Keluarga merupakan lembaga utama yang berperan besar dalam mempromosikan masyarakat yang harmonis dan berpengetahuan luas. Orang tua memiliki penanan yang sangat penting dalam pendidikan anak mereka, baik pendidikan di rumah maupun disekolah. Dukungan status ekonomi keluarga dipandang menjadi salah satu faktor penting dalam mempengaruhi prestasi belajar siswa (Mansora \& Ahmada, 2016). Perhatian orang tua merupakan pertimbangan energi orang tua yang disengaja, terkonsentrasi berdasarkan rasa kesadaran penuh, tanggung jawab, dan kasih sayang untuk pencapaian suatu hasil belajar yang memuaskan (Haditama, Wardi \& Syamwil, 2018). perhatian orang tua ialah pemusatan suatu energi psikis secara yang tertujuan pada suatu objek, dalam hal ini anak yang dilakukan oleh ayah dan ibu atau wali yang dilakukan dalam suatu aktivitas tertentu (Handayani, 2014). Perhatian orang tua terhadap anak dalam proses belajar dibagi menjadi 2 yaitu perharian fisik dan psikis. Perhatian fisik yang diwujudkan dalam pemenuhan kebutuhan material seperti: menyediakan tempat untuk belajar, memberikan peralatan belajar, memberikan suatu hadiah, menjaga supaya anak tubuh sehat, memberikan uang yang digunakan untuk keperluan belajar. Kebutuhan spikis seperti: mengarahkan anak dalam berteman, memberikan kontrol dalam tontonan TV, memberikan kontorl dalam bacaan yang dibaca anak dan mengontrol kegiatan anak.

Menurut Prasetyo, kebutuhan fisik dapat berupa menyediakan tempat belajar yang nyaman dalam belajar, menyediakan peralatan yang dibutuhkan anak untuk belajar, memberikan teguran jika anak berbuat salah ketika tidak mengerjakan PR sekolah, menyediakan vitamin daalm upaya meningkatkan kesehatan anak dan memberikan uang saku untuk keprluan anak sekolah. Sedangkan kebutuhan psikis antara lain orang tua dapat mengarahkan anak untuk bergaul dengan teman yang baik, memberikan nasehat kepada anak, memeriksa hasil peroses belajar disekolah, mengingatkan anak untuk rajin beribadah dan membantu anak jika kesusahan dalam belajar (Prasetyo et. al, 2021).

(Ambarwati, 2018). Suatu bentuk perhatian yang diberikan orang tua terhadap anak dengan memberikan hak pada anaknya, hak mendapatkan perhatian fisik dan juga perhatian psikis antara lain: Memilih lingkungan yang baik, mendoakan anak-anaknya, merawat, mendidik dan melatih anak-anaknya, memberikan rasa aman, memberikan kasih sayang, memberikan pembinaan keagamaaan, memberikan pendidikan dan bimbingan, mencukupi kebutuhan hidupnya (Helmawati, 2016). 
Peran guru merupakan istilah yang digunakan untuk manifestasi perilaku dari tindakan mengajar yang mencakup semua perilaku verbal dan non verbal yang ditunjukan oleh seorang guru dalam upaya untuk memberikan pendidikan dalam lingkungan pembelajaran di sekolah. Pengembangan kapasistas akademik dan perilaku guru tidak hanya membantu guru memperolah sikap mengajar yang benar, akan tetapi dapat berdampak pada peningkatan kemampuan belajar siswa. Guru dapat memainkan peran utama dalam meningkatkan kemampuan belajar (Rashid \& SaeedUzZaman, 2018). Sebagai bagian dari manajemen kelas, peran atau perilaku guru sangat penting dalam meningkatkan keberhasilan prestasi akademik siswa. Seorang guru harus tekun, tulus, jujur ,fleksibel dan bijaksana dalam membimbing siswa (Mehdipour \& Balaramulu, 2013). Peran guru dikelas maupun dalam pembelajaran during sangat penting untuk mewujudkan pengajaran yang efektif. Beberapa peran guru dalam kegiatan pembelajaran disekolah adalah guru sebagai: pemberi informasi, penyelengara kegiatan pembelajaran, yang memprakarsai (inisiator), yang menyediakan fasilitas (fasilitator), sebagai pendorong (motivator) dan yang memberikan penilaian dalam proses pembelajaran (Tambunan, 2018). Peran guru adalah kecenderungan seorang guru untuk berbuati secara positif atau secara negatif, memberikan dukungan atau tidak memberikan suatu dukungan dalam melakukan tindakan, menyampaikan pendapat, memberikan pandangan, nilai dan memerikan tingkah laku siswa. Peran guru tersebut dapat di praktekan dalam tindakan seperti: memberikan kepedulian yang tulus dari hati dan melakukan kebaikan dari seorang guru terhadap siswa, bersedia berbagi tanggung jawab didalam kelas, memberikan kepekaan yang tulus terhadap kondisi keragaman siswa, memberikan motivasi untuk berbagi pengalaman belajar yang bermakna untuk semua siswa, dan antusias untuk memberikan rangsangan kreatifitas siswa (Kardo, \& Yuzarion, 2017).

Menurut Alfitriyani motivasi belajar adalah suatu dorongan dari internal dan eksternal kepada siswa yang sedang menuntut ilmu untuk melakukan suatu perubahan perilaku, umumnya dengan beberapa indikator atau elemen pendukung seperti: ada suatu tindakan untuk berhasil, ada suatu dorongan dan suatu kebutuhan dalam belajar, adanya suatu harapan dan cita-cita akan masa depan, adanya apresiasi dalam pembelajaran, ada kegiatan yang dapat menarik dalam proses pembelajaran, dan adanya lingkungan tempat belajar yang kondusif sehingga siswa dapat belajar dengan baik (Alfitriyani, 2019). Ambarwati berpendapat motivasi belajar adalah salah satu bentuk dorongan belajar yang muncul dengan adanya suatu hal yang baik dari sebuah diri individu atau dari lingkungan. Motivasi belajar sendiri terdiri dari tinggi dari beberapa bagian, yaitu: (1) Suatu kenikmatan dalam belajar dan saat mengerjakan suatu tugas sekolah, (2) orientasi kepada penguasaan materi yaitu suatu kemampuan siswa dalam menguasai suatu materi yang disajikan dalam proses pembelajaran di sekolah, (3) keinginan untuk mengetahui yaitu keinginan seorang siswa yang dapat mendorongan individu untuk mencari suatu hal baru dan mencarinya lebih jauh lagi, (4) ketahanan dalam bekerja tugas yaitu siswa berfokus sepenuhnya untuk dapat menyelesaikan suatu tugas dan tidak mudah untuk menyerah atau putus asa dalam menyelesaikan tugas tersebut, (5) Orientasi ke tugas yaitu siswa rajin mengerjakan suatu tugas, konsentrasi pada tugas dan siswa termokultur untuk menyelesaikan suatu tugas yang sulit atau baru daripada yang mudah atau rutin tugas (Ambarwati, 2018).

Penelitian yang dilakukan oleh Fijar, Muchtar, \& Idris, yang berjudul The Effect of Parental Attention, Home Study Facilities and 
Learning Motivation on Students Learning Outcome (Research : Social Sciense Subject in District Sungayang High School Tanah Datar Regency) diproleh kesimpulan bahwa Perhatian orang tua mempunyai pengaruh yang signifikan dalam memotivasi siswa untuk belajar pada mata pelajaran IPS di SMA Kecamatan Sungayang (Fijar, Muchtar, \& Idris, 2019). Hal ini sejalan dengan penelitian yang dilakukan oleh Vinorita, \& Muhsin, yang salah satunya tentang Pengaruh perhatian orang tua, terhadap motivasi belajar siswa, diperoleh kesimpulan bahwa Perhatian orang tua secara parsial mempunyai pengaruh dalam motivasi siswa dalam proses pembelajaran pada suatu Program Keahlian Administrasi Perkantoran di SMK Teuku Umar Semarang tahun ajaran 2017/2018. (Fijar, Muchtar, \& Idris, 2019). Sedangkan penelitian yang dilakukan oleh Prianto, \& Putri yang berjudul Pengaruh Ketersediaan Fasilitas Belajar, Dukungan Orang Tua Yang Dirasakan Terhadap motivasi Dan Prestasi Belajar Siswa SMA PGRI Ngimbang Lamongan diperoleh kesimpulan bahwa tidak adanya suatu pengaruh yang secara positif dan signifikan antara suatu yang mendukung dari orang tua siswa, dalam memotivasi belajar siswa SMA PGRI Ngimbang Lamongan (Prianto, \& Putri, 2017).

Penelitian yang dilakukan oleh Yurniati, D, Syofyan, E., \& Marwan. Yang berjudul The Effect of Teacher's Role, Learning Motivation and Students' Creativity toward Learning Outcome on Workshop and Entrepreneurship's Subject of XI Grade Studentsin Management Business Vocational School in Padang City, diperoleh kesimpulan bahwa peran Guru mempunyai pengaruh yang positif dan signifikan dalam memotivasi belajar siswa kelas X SMK Manajemen Bisnis Padang (Yurniati et. al., 2018). Penelitian yang dilakukan oleh Darmawan yang salah satunya tentang Pengaruh Peran Guru dalam meningkatkan Motivasi Belajar Penjas SD Inpres Buttatianang I Makassar, diperoleh kesimpulan bahwa adanya pengaruh peran seorang guru dalam memotivasi belajar siswa pada mata pelajaran pendidikan jasmani (Penjas) (Darmawan, 2018). Penelitian yang dilakukan oleh Tambunan dengan judul The Dominant Factor of Teacher's Role as A Motivator of Students' Interest and Motivation in Mathematics Achievement diperoleh kesimpulan bahwa peran guru menjadi faktor yang dominan untuk memotivasi siswa, dengan indikator dapat menyampaikan tujuan pembelajaran, kenyamanan pembelajaran dan variasi pendekatan pembelajaran membuat siswa senang belajar dan mempengaruhi motivasi siswa terhadap prestasi belajar matematika (Tambunan, 2018).

Dengan adannya wabah pandemik Covid19, mengharuskan pembelajaran dilakukan dengan sitem during sehingga timbuk beberapa masalah antara lain guru harus menyesuaikan dengan teknologi dalam penyapaian materi sedangkan orang tua harus dapat memberikan suatu perhatian yang lebih untuk anak-anaknya. Permasalahan dalam penelitian ini adalah apakah konstruk laten eksogen: perhatian orang tua dan peran seorang guru berpengaruh secara positif dan signifikan terhadap konstruk laten endogen: motivasi belajar siswa semasa pandemik Covid-19 di Sekolah Dasar Islam Assakinah Batam. Penelitian ini bertujuan untuk menguji dan menganalisis pengaruh konstruk laten eksogen: perhatian orang tua dan peran guru terhadap kontruk laten endogen: motivasi belajar siswa semasa pandemik Covid19 di Sekolah Dasar Islam Assakinah Batam.

\section{METODE}

Model penelitian ini termasuk dalam jenis penelitian yang dilakukan peneliti merupapakan penelitian lapangan dengan memakai metode penelitian kuantitatif atau positivistik. Metode atau jenis penelitian kuantitatif disebut juga sebagai metode positivistik karena didasarkan pada filosofi positivistme (Sugiyono, 2017). Jenis data yang dipakai dalam penelitian ini 
merupakan jenis data primer. Data primer adalah sumber data yang memberikan langsung datanya kepada pengumpul data. (Sugiyono, 2017).

Penelitian ini dimulai pada bulan Agustus sampai bulan Desember 2020 bertempat di Sekolah Dasar Islam Assakinah yang berlamat di Perum Bumi Sakinah, Tembesi, Sagulung, Batam.Populasi adalah keseluruhan suatu subjek yang dilakukan penelitian (Arikunto, 2014) Populasi dalam penelitian ini merupakan seluruh siswa Sekolah Dasar Islam Assakinah Batam yang berjumlah 360 orang atau siswa. Sampel mempunyai pengertian sebagian atau wakil populasi yang diteliti (Arikunto, 2014). Bila populasi mempunyai jumlah terlalu banyak (besar), dan peneliti mustahil akan mengambil sampel secara keseluruhan dan mempelajari semua yang ada pada populasi, oleh karena itu peneliti dapat melakukan pengambilan beberapa sampel yang diambil dari populasi itu untuk diolah. Jumlah sampel yang diambil dalam penelitian ini, peneliti menggunakan rumus Slovin sebagai berikut: $\mathrm{n}=\mathrm{N} /\left(1+\mathrm{Ne}^{2}\right)$, dimana $\mathrm{n}=$ jumlah sampel, $\mathrm{N}=$ populasi dan $\mathrm{e}=$ error tolerance (Supriyanto \& Iswandiri, 2017). Pada penelitian ini dengan e (error tolerance $)=5 \%$, maka jumlah sampel yang diambil sebanyak 190 orang siswa. Teknik analisis atau teknik pengujian hipotesis dalam penelitian ini menggunakan metode structural equation model atau disingkat SEM. Perangkat lunak yang digunakan untuk analisis struktural adalah AMOS 22. Pada analisis dengan menggunakan structural equation model (SEM) sendiri, ukuran sampel yang direkomendasikan adalah antara 100 sampai 200 orang (Yasa et. al., 2020).

Instrumen yang dipilih Peneliti dalam melkukan penelitian ini adalah berupa kuesioner atau dapat juga disebut angket. Kuesioner atau angket merupakan suatu instrumen dalam pengumpulan data dimana peserta/ responden melakukan pengisian pertanyaan atau peryataan yang disediakan dan diberikan oleh peneliti, kemudian dikembalikan lagi kepada peneliti setelah diisi (Sugiyono, 2017).

Pada penelitian ini, dikarenakan anggota populasi dianggap homogen, maka teknik pengumpulan data (sampling) menggunakan teknik simple random sampling. Dikatakan simple (sederhana) karena pengambilan anggota sample dari populasi oleh seorang peneliti dilakukan secara acak tanpa memperhatikan strata yang ada dalam populasi (Sugiyono, 2017).

Pada model penelitian ini terdapat 3 variabel yaitu 2 variabel eksogen yaitu: perhatian orang tua, dan peran guru, dan 1 variabel endogen yaitu: motivasi belajar.

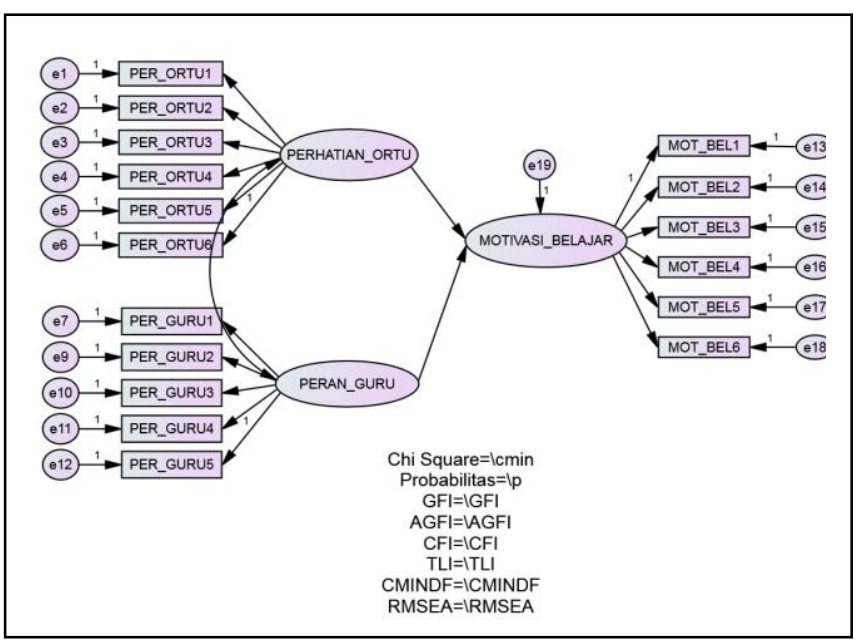

Gambar 1.

Model penelitian pengaruh perhatian orang tua dan peran guru terhadap motivasi belajar siswa semasa pandemik covid-19.

Hipotesis pada penelitian ini adalah:

$H_{1}=$ Terdapat pengaruh yang positif dan signifikan perhatian orang tua terhadap motivasi belajar siswa semasa pandemik covid-19 di Sekolah Dasar Islam Assakinah Batam.

$H_{2}=$ Terdapat pengaruh yang positif dan signifikan peran guru terhadap motivasi belajar siswa semasa pandemik covid-19 di Sekolah Dasar Islam Assakinah Batam. 


\section{HASIL DAN PEMBAHASAN}

\section{Hasil}

\section{a. Analisis faktor konfirmatori}

(confirmatory factor analysis)

Dalam menganalisis faktor konfirmatori tiap variabel, peneliti menggunakan 3 ukuran validitas konstruk yaitu: covergent validity, variance extract dan reliability (Ghozali, 2017).

\section{1) Analisis faktor konfirmatori variabel perhatian orang tua}

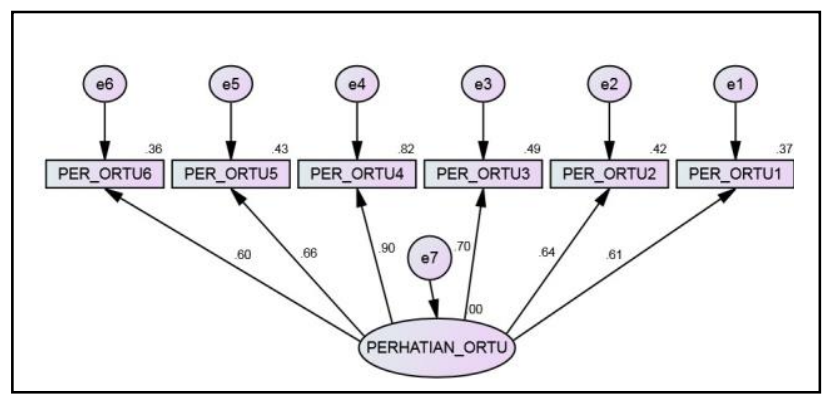

Gambar 2.

Confirmatory Factor Analysis Variabel Perhatian Orang Tua

Tabel 1

Regression Weights Indikator Perhatian Orang Tua

\begin{tabular}{|c|l|l|l|l|l|}
\hline & Estimate & S.E. & C.R. & P & Label \\
\hline PER_ORTU6 & 1.000 & & & & \\
\hline PER_ORTU5 & 1.119 & .153 & 7.315 & $* * *$ & par_1 \\
\hline PER_ORTU4 & 1.456 & .168 & 8.678 & $* * *$ & par_2 \\
\hline PER_ORTU3 & 1.175 & .154 & 7.612 & $* * *$ & par_3 \\
\hline PER_ORTU2 & 1.055 & .148 & 7.108 & $* * *$ & par_4 \\
\hline PER_ORTU1 & 1.015 & .148 & 6.863 & $* * *$ & par_5 \\
\hline
\end{tabular}

Tabel 2.

Standardized Regression Weights Indikator Perhatian Orang Tua

\begin{tabular}{|l|c|}
\hline & Estimate \\
\hline PER_ORTU6<---PERHATIAN_ORTU & 0,714 \\
\hline PER_ORTU5<---PERHATIAN_ORTU & 0,650 \\
\hline PER_ORTU4<---PERHATIAN_ORTU & 0,914 \\
\hline PER_ORTU3<---PERHATIAN_ORTU & 0,703 \\
\hline PER_ORTU2<---PERHATIAN_ORTU & 0,631 \\
\hline PER_ORTU1<---PERHATIAN_ORTU & 0,615 \\
\hline
\end{tabular}

a) Convergent validty variabel perhatian orang tua.

Hasil dari analisis faktor konfirmatori terhadap indikator variabel Perhatian Orang
Tua, dapat dilihat pada Tabel 1, semua indikator adalah signifikan. Semua loading faktor $>0.5$, hal ini dapat dilihat pada Gambar 2 maupun pada Tabel 2. Dengan demikian untuk Convergent validity untuk ke 6 indikator variabel pengaruh perhatian orang terpenuhi (Ghozali, 2017).

b) Variance extracted variabel perhatian orang tua.

Dalam analisis konfirmatori, prosentase rata-rata nilai variance extraced (AVE) antar indikator variabel perhatian orang tua, untuk memudahkannya diringkas dalam sebuah Tabel 3 dibawah ini:

Tabel 3.

Perhitungan Variance extracted dan Construct Reliabilty Perhatian Orang Tua

\begin{tabular}{|c|c|c|c|}
\hline Indikator & $\begin{array}{c}\text { Loading } \\
\text { Faktor } \\
(\lambda)\end{array}$ & $\lambda^{2}$ & $1-\lambda^{2}$ \\
\hline PER_ORTU6 & 0,714 & 0,510 & 0,490 \\
\hline PER_ORTU5 & 0,650 & 0,423 & 0,578 \\
\hline PER_ORTU4 & 0,914 & 0,835 & 0,165 \\
\hline PER_ORTU3 & 0,703 & 0,494 & 0,506 \\
\hline PER_ORTU2 & 0,631 & 0,398 & 0,602 \\
\hline PER_ORTU1 & 0,615 & 0,378 & 0,622 \\
\hline TOTAL & 4,227 & 3,038 & 2,962 \\
\hline
\end{tabular}

Dari Tabel 3 variance extraced $(\mathrm{AVE})=$ $3,038 /(3,038+2,962)=0,506$. Jadi dapat disimpulkan bahwa variabel perhatian orang tua memenuhi kriteria variance extraced (AVE), karena 0,506 > 0.5 (Ghozali, 2017)

c) Construct Reliabilty variabel perhatian orang tua.

Dalam analisis konfirmatori, Construct Reliabilty perhatian orang tua, untuk memudahkan dapat berpedoman pada Tabel 3. Dari data tabel tersebut, masukan ke dalam rumus Construct Reliabilty (CR) = $4,227^{2} /\left(4,227^{2}+2,962\right)=0,858$. Jadi dapat disimpulkan bahwa variabel perhatian orang tua memenuhi kriteria Construct Reliabilty (CR), karena 0,858 > 0,7 (Ghozali, 2017). 
2) Analisis faktor konfirmatori variabel peran guru.

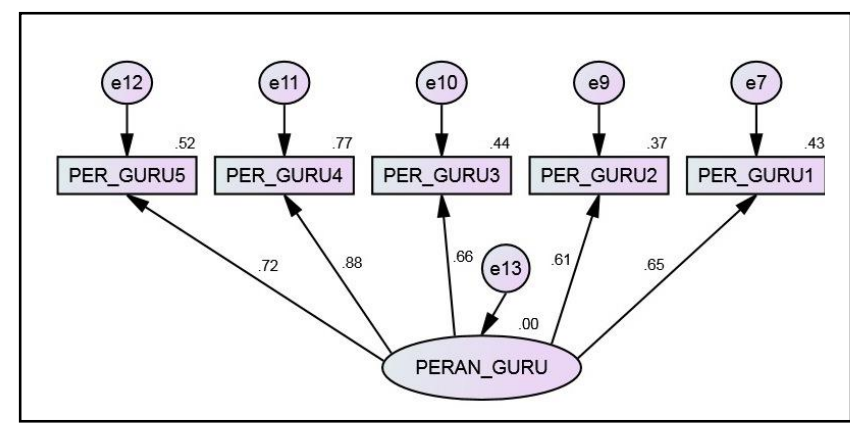

Gambar 3.

Confirmatory Factor Analysis Variabel Peran Guru

Tabel 4.

Regression Weights Indikator peran guru.

\begin{tabular}{|l|r|r|r|c|c|}
\hline & Estimate & S.E. & C.R. & P & Label \\
\hline PER_GURU5 & 1.000 & & & & \\
\hline PER_GURU4 & 1.221 & .117 & 10.446 & $* * *$ & par_1 \\
\hline PER_GURU3 & .935 & .111 & 8.427 & $* * *$ & par_2 \\
\hline PER_GURU2 & .897 & .116 & 7.714 & $* * *$ & par_3 \\
\hline PER_GURU1 & .976 & .117 & 8.321 & $* * *$ & par_4 \\
\hline
\end{tabular}

Tabel 5.

Standardized Regression Weights Indikator Peran Guru.

\begin{tabular}{|c|c|}
\hline & Estimate \\
\hline PER_GURU5<---PERAN_GURU & 0.722 \\
\hline PER_GURU4<---PERAN_GURU & 0.876 \\
\hline PER_GURU3<---PERAN_GURU & 0.661 \\
\hline PER_GURU2<---PERAN_GURU & 0.609 \\
\hline PER_GURU1<---PERAN_GURU & 0.654 \\
\hline
\end{tabular}

a) Convergent validty variabel peran guru.

Berdasarkan hasil analisis faktor konfirmatori terhadap indikator variabel peran guru, dapat dilihat pada Tabel 4, semua indikator adalah signifikan. Semua loading faktor > 0.5, hal ini dapat dilihat pada Gambar 3 maupun pada Tabel 5. Dengan demikian untuk Convergent validity untuk ke 5 indikator variabel peran guru terpenuhi (Ghozali, 2017).

b) Variance extracted variabel peran guru.

Dalam analisis konfirmatori, prosentase rata-rata nilai variance extraced (AVE) antar indikator variabel peran guru, untuk memudahkannya diringkas dalam sebuah Tabel 6 dibawah ini:

Tabel 6.

Perhitungan Variance extracted dan Construct Reliabilty Peran Guru.

\begin{tabular}{|c|c|c|c|}
\hline Indikator & $\begin{array}{c}\text { Loading } \\
\text { Faktor } \\
(\lambda)\end{array}$ & $\lambda^{2}$ & $1-\lambda^{2}$ \\
\hline PER_GURU5 & 0,722 & 0,521 & 0,479 \\
\hline PER_GURU4 & 0,876 & 0,767 & 0,233 \\
\hline PER_GURU3 & 0,661 & 0,437 & 0,563 \\
\hline PER_GURU2 & 0,609 & 0,371 & 0,629 \\
\hline PER_GURU1 & 0,654 & 0,428 & 0,572 \\
\hline TOTAL & 3,522 & 2,524 & 2,476 \\
\hline
\end{tabular}

Dari Tabel 6 variance extraced $(\mathrm{AVE})=$ $2,524 /(2,524+2,476)=0,505$. Jadi dapat disimpulkan bahwa variabel peran guru memenuhi kriteria variance extraced (AVE), karena 0,505 > 0.5 (Ghozali, 2017).

c) Construct Reliabilty variabel peran guru.

Dalam analisis konfirmatori, Construct Reliabilty peran guru, untuk memudahkan dapat berpedoman pada Tabel 6. Dari data tabel tersebut, masukan ke dalam rumus Construct Reliabilty (CR) = $3,522^{2} /\left(3,522^{2}+2,476\right)=0,834$. Jadi dapat disimpulkan bahwa variabel peran guru memenuhi kriteria Construct Reliabilty (CR), karena 0,834 > 0,7 (Ghozali, 2017).

\section{3) Analisis faktor konfirmatori variabel motivasi belajar.}

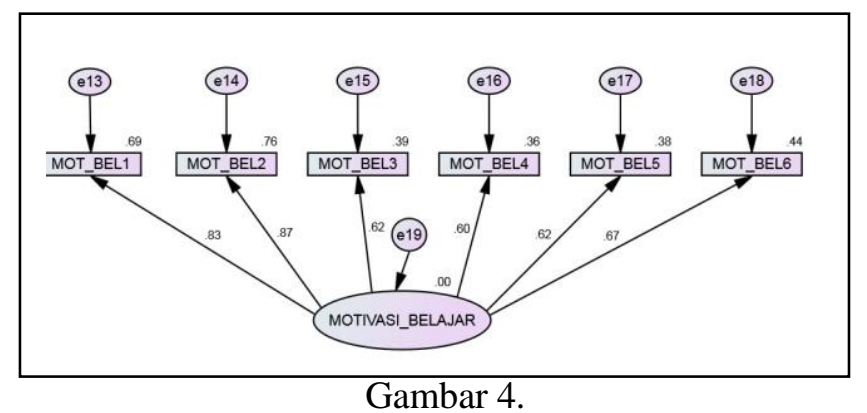

Confirmatory Factor Analysis Variabel Motivasi Belajar.

Tabel 7.

Regression Weights Indikator Motivasi Belajar.

\begin{tabular}{|c|c|c|c|c|c|}
\hline & $\begin{array}{c}\text { Estimat } \\
\mathrm{e}\end{array}$ & S.E. & C.R. & $\mathrm{P}$ & $\begin{array}{c}\text { Labe } \\
1\end{array}$ \\
\hline MOT_BEL & 1.000 & & & & \\
\hline
\end{tabular}




\begin{tabular}{|c|c|c|c|c|c|}
\hline & $\begin{array}{c}\text { Estimat } \\
\mathrm{e}\end{array}$ & S.E. & C.R. & $\mathrm{P}$ & $\begin{array}{c}\text { Labe } \\
1\end{array}$ \\
\hline 1 & & & & & \\
\hline${ }_{2}$ MOT_BEL & 1.099 & $\begin{array}{r}.08 \\
0 \\
\end{array}$ & $\begin{array}{r}13.67 \\
9 \\
\end{array}$ & $\begin{array}{r}* * \\
* \\
\end{array}$ & $\begin{array}{c}\mathrm{par}_{-} \\
1\end{array}$ \\
\hline $\mathrm{MOT}_{3}$ _BEL & 1.304 & $\begin{array}{r}.14 \\
5\end{array}$ & 8.982 & $\begin{array}{r}* * \\
*\end{array}$ & $\underset{2}{\text { par_ }_{2}}$ \\
\hline MOT_BEL $_{4}$ & .747 & $\begin{array}{r}.08 \\
9\end{array}$ & 8.418 & $\begin{array}{r}* * \\
*\end{array}$ & $\begin{array}{c}\text { par_ }_{3} \\
\text { - }\end{array}$ \\
\hline MOT_BEL & .991 & $\begin{array}{r}.11 \\
4\end{array}$ & 8.712 & $\begin{array}{r}* * \\
*\end{array}$ & $\underset{4}{\mathrm{par}_{-}}$ \\
\hline $\mathrm{MOT}_{\frac{6}{\mathrm{~B}} \mathrm{BEL}}$ & .914 & $\begin{array}{r}.09 \\
6\end{array}$ & 9.563 & $\begin{array}{r}* * \\
*\end{array}$ & $\underset{5}{\mathrm{par}_{-}}$ \\
\hline
\end{tabular}

Tabel 8.

Standardized Regression Weights Indikator Motivasi Belajar.

\begin{tabular}{|c|c|}
\hline & Estimate \\
\hline $\begin{array}{c}\text { MOT_BEL1<--- } \\
\text { MOTIVASI_BELA }\end{array}$ & 0.831 \\
\hline $\begin{array}{c}\text { MOT_BEL2<--- } \\
\text { MOTIVASI_BELA }\end{array}$ & 0.873 \\
\hline $\begin{array}{r}\text { MOT_BEL3<--- } \\
\text { MOTIVASI_BELA }\end{array}$ & 0.624 \\
\hline $\begin{array}{r}\text { MOT_BEL4<--- } \\
\text { MOTIVASI_BELA }\end{array}$ & 0.598 \\
\hline $\begin{array}{r}\text { MOT_BEL5<--- } \\
\text { MOTIVASI_BELA }\end{array}$ & 0.618 \\
\hline $\begin{array}{r}\text { MOT_BEL6<--- } \\
\text { MOTIVASI_BELA }\end{array}$ & 0.666 \\
\hline
\end{tabular}

a) Convergent validty variabel motivasi belajar.

Hasil dari analisis faktor konfirmatori terhadap indikator variabel motivasi belajar, dapat dilihat pada Tabel 7, semua indikator adalah signifikan. Semua loading faktor > 0.5, hal ini dapat dilihat pada Gambar 4 maupun pada Tabel 8. Dengan demikian untuk Convergent validity untuk ke 6 indikator variabel motivasi belajar terpenuhi (Ghozali, 2017).

b) Variance extracted variabel motivasi belajar. Pada analisis konfirmatori, prosentase ratarata dari nilai variance extraced (AVE) antar indikator variabel motivasi belajar, untuk memudahkannya diringkas dalam sebuah Tabel 9 dibawah ini:

Tabel 9.
Perhitungan Variance extracted dan Construct Reliabilty Motivasi Belajar

\begin{tabular}{|c|c|c|c|}
\hline Indikator & $\begin{array}{c}\text { Loading } \\
\text { Faktor } \\
(\lambda)\end{array}$ & $\lambda^{2}$ & $1-\lambda^{2}$ \\
\hline MOT_BEL1 & 0,831 & 0,691 & 0,309 \\
\hline MOT_BEL2 & 0,873 & 0,762 & 0,238 \\
\hline MOT_BEL3 & 0,624 & 0,389 & 0,611 \\
\hline MOT_BEL4 & 0,598 & 0,358 & 0,642 \\
\hline MOT_BEL5 & 0,618 & 0,382 & 0,618 \\
\hline MOT_BEL6 & 0,666 & 0,444 & 0,556 \\
\hline TOTAL & 4,210 & 3,025 & 2,975 \\
\hline
\end{tabular}

Dari Tabel 9 variance extraced $(\mathrm{AVE})=$ $3,025 /(3,025+2,975)=0,504$. Jadi dapat disimpulkan bahwa variabel motivasi belajar memenuhi kriteria variance extraced (AVE), karena 0,504 > 0.5 (Ghozali, 2017).

c) Construct Reliabilty variabel motivasi belajar.

Dalam analisis konfirmatori, Construct Reliabilty motivasi belajar, untuk memudahkan dapat berpedoman pada Tabel 9. Dari data tabel tersebut, masukan ke dalam rumus Construct Reliabilty $(\mathrm{CR})=$ $4,210^{2} /\left(4,210^{2}+2,975\right)=0,856$. Jadi dapat disimpulkan bahwa variabel motivasi belajar memenuhi kriteria Construct Reliabilty (CR), karena 0,856 > 0,7 (Ghozali, 2017).

\section{b. Analisis dengan SEM (structural} equation model

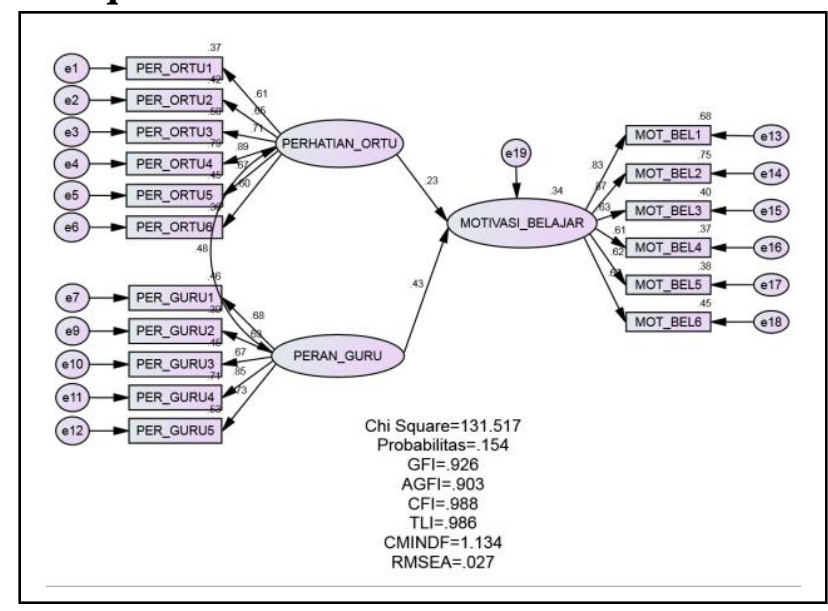

Gambar 5.

Analisis dengan SEM (structural equation model) Pengaruh Perhatian Orang Tua dan Peran Guru Terhadap Motivasi Belajar Siswa Semasa Pandemik Covid-19 


\section{c. Analisis Model Persamaan Struktural}

Persamaan struktur perhatian orang tua $\left(x_{1}\right)$ dan motivasi belajar (Y) adalah sebagai berikut:

$H_{1}: \mathrm{Y}=\gamma_{y, x_{1}} x_{1}+e_{1}$ berpengaruh secara positif dan signifikan $x_{1}$ terhadap $\mathrm{Y}$

$H_{2}: \mathrm{Y}=\gamma_{y, x_{2}} x_{2}+e_{2}$ berpengaruh secara positif dan signifikan $x_{2}$ terhadap Y

Tabel 10.

Standardized Direct Effects (Group number 1 Default model)

\begin{tabular}{|r|r|r|r|}
\hline & $\begin{array}{r}\text { PERAN } \\
\text { _GURU }\end{array}$ & $\begin{array}{c}\text { PERHATI } \\
\text { AN_ORT } \\
\text { U }\end{array}$ & $\begin{array}{r}\text { MOTIVASI } \\
\text { _BELAJAR }\end{array}$ \\
\hline $\begin{array}{r}\text { MOTIVASI } \\
\text { BELAJAR }\end{array}$ & 0,441 & 0,212 & 0,000 \\
\hline
\end{tabular}

Tabel 11.

Regression Weights: (Group number 1 - Default model)

\begin{tabular}{|r|c|c|c|c|c|}
\hline & $\begin{array}{c}\text { Esti } \\
\text { mate }\end{array}$ & S.E. & C.R. & P & $\begin{array}{c}\text { La } \\
\text { bel }\end{array}$ \\
\hline $\begin{array}{r}\text { MOTIVASI } \\
\text { _BELAJAR } \\
<---\end{array}$ & .236 & .095 & 2.476 & .013 & $\begin{array}{c}\text { par } \\
-1 \\
5\end{array}$ \\
$\begin{array}{r}\text { PERHATIA } \\
\text { N_ORTU }\end{array}$ & & & & & \\
\hline $\begin{array}{r}\text { MOTIVASI } \\
\text { BELAJAR } \\
<---\end{array}$ & .499 & .106 & 4.714 & $* * *$ & $\begin{array}{c}\text { par } \\
-1 \\
7\end{array}$ \\
$\begin{array}{r}\text { PEATAN } \\
\text { GURU }\end{array}$ & & & & & \\
\hline
\end{tabular}

Tabel 12 .

Standardized Regression Weights: (Group number 1 - Default model

\begin{tabular}{|c|c|}
\hline & Estimate \\
\hline $\begin{array}{c}\text { MOTIVASI_BELAJAR<--- } \\
\text { PERHATIAN_ORTU }\end{array}$ & 0,212 \\
\hline $\begin{array}{c}\text { MOTIVASI_BELAJAR<--- } \\
\text { PERAN_GURU }\end{array}$ & 0,441 \\
\hline
\end{tabular}

\section{Pembahasan}

Data hasil penelitian diatas, pengaruh variabel exogen laten perhatian orang tua terhadap variabel endogen laten motivasi belajar siswa semasa pandemik Covid-19 mempunyai standardized estimate (regression weight) sebesar 0,236 dengan CR (Critical ratio) $=$ 2,476 dan probability $=0,013$. Nilai CR 2,276>
2,000 dan Probability $=0,013<0,05$ menunjukkan bahwa pengaruh variabel exogen perhatian orang tua terhadap variabel endogen motivasi belajar siswa semasa pandemik Covid19 di Sekolah Dasar Islam Assakinah Batam adalah positif signifikan.

Hasil ini sesuai dengan Penelitian yang dilakukan oleh Fijar, Muchtar, \& Idris, yang berjudul The Effect of Parental Attention, Home Study Facilities and Learning Motivation on Students Learning Outcome (Research : Social Sciense Subject in District Sungayang High School Tanah Datar Regency) yang diproleh kesimpulan bahwa Perhatian orang tua mempunyai pengaruh yang signifikan dalam memotivasi siswa untuk belajar pada mata pelajaran IPS di SMA Kecamatan Sungayang (Fijar, Muchtar, \& Idris, 2019), dan juga sejalan dengan penelitian yang dilakukan oleh Vinorita, \& Muhsin, yang berjudul Pengaruh salah satunya tentang Pengaruh perhatian orang tua, terhadap motivasi belajar siswa, diperoleh kesimpulan bahwa bahwa Perhatian orang tua secara parsial mempunyai pengaruh dalam motivasi siswa dalam proses pembelajaran pada Program Keahlian Administrasi Perkantoran di SMK Teuku Umar Semarang tahun ajaran 2017/2018. (Fijar, Muchtar, \& Idris, 2019). Selain itu hasil penelitian ini juga menguatkan pendapat dari Garbe yang menyatakan dukungan dan tanggung jawab orang tua menunjukkan peran yang signifikan saat anakanak mereka berpartisipasi dalam pendidikan during sehingga dapat memotivasi anak untuk mencapai keberhasilan dalam pembelajaran during (Garbe et. al., 2020).

Dengan memperhatikan standardized estimate variabel exogen laten perhatian orang tua dan variabel endogen laten motivasi belajar maka dapat dibuat model persamaan strukturan sebagai berikut:

$H_{1}: \mathrm{Y}=\gamma_{y, x_{1}} x_{1}+e_{1} \rightarrow=0,198 x_{1}+e_{1}$ (Positif, Signifikan). 
Pengaruh variabel exogen laten peran guru terhadap variabel endogen laten motivasi belajar siswa semasa pandemik Covid-19 mempunyai standardized estimate (regression weight) sebesar 0,499 dengan CR (Critical ratio) = 4,714 dan probability $=0,000$. Nilai CR 4,714> 2,000 dan Probability $=0,000<0,05$ menunjukkan bahwa pengaruh variabel exogen peran guru terhadap variabel endogen motivasi belajar siswa semasa pandemik Covid-19 di Sekolah Dasar Islam Assakinah Batam adalah positif signifikan.

Hasil ini sesuai dengan Penelitian yang dilakukan oleh Yurniati, D, Syofyan, E., \& Marwan. Yang berjudul The Effect of Teacher's Role, Learning Motivation and Students' Creativity toward Learning Outcome on Workshop and Entrepreneurship's Subject of XI Grade Studentsin Management Business Vocational School in Padang City, yang diperoleh kesimpulan bahwa peran Guru mempunyai pengaruh yang positif dan signifikan dalam memotivasi belajar siswa kelas X SMK Manajemen Bisnis Padang (Yurniati et. al., 2018). Selain itu juga sesuai dengan Penelitian yang dilakukan oleh Darmawan yang yang salah satunya tentang Pengaruh Peran Guru dalam meningkatkan Motivasi Belajar Penjas SD Inpres Buttatianang I Makassar , yang diperoleh kesimpulan bahwa terdapat peran guru mempunyai pengaruh dalam memotivasi belajar siswa pada mata pelajaran pendidikan jasmani (Penjas) (Darmawan, 2018), dan juga penelitian yang dilakukan oleh Tambunan yaitu tentang The Dominant Factor of Teacher's Role as A Motivator of Students' Interest and Motivation in Mathematics Achievement, yang diperoleh kesimpulan bahwa peran guru menjadi faktor yang dominan untuk memotivasi siswa dengan indikator penyampaian tujuan pembelajaran, kenyamanan pembelajaran dan variasi pendekatan pembelajaran membuat siswa senang belajar dan mempengaruhi motivasi siswa terhadap prestasi belajar matematika (Tambunan, 2018).

Dengan memperhatikan standardized estimate variabel exogen laten perhatian orang tua dan variabel endogen laten motivasi belajar maka dapat dibuat model persamaan strukturan sebagai berikut:

$H_{2}: \mathrm{Y}=\gamma_{y, x_{2}} x_{2}+e_{2} \rightarrow=0,443 x_{2}+e_{2}$. (Positif, signifikan)

Analisis model pengukuran dengan Squared Multiple Correlations.

Analisis model pengukuran dengan koefisien determinasi atau disebut dengan $R^{2}$ digunakan untuk melihat seberapa pengaruh yang ditimbulkan oleh variabel eksogen: perhatian orang tua dan peran guru terhadap tingkat perubahan variabel endogen: motivasi belajar, untuk nalisis ini digunakan Square Multiple Correlation. Besarnya Square Multiple Correlation dapat dilihat pada Tabel 13. Berikut ini:

Tabel 13.

Squared Multiple Correlations

\begin{tabular}{|c|c|}
\hline & Estimate \\
\hline MOTIVASI_BELAJAR & 0.328 \\
\hline
\end{tabular}

Square Multiple Correlation yang nilainya 0.323 menunjukan besarnya pengaruh variabel exogen laten perhatian orang tua dan peran guru terhadap variabel endogen laten motivasi belajar siswa semasa pandemik Covid-19 di Sekolah Dasar Islam Assakinah Batam adalah 0.328 x $100 \%=32,8 \%$. Perhatian orang tua semasa pandemik Covid-19 dilakukan dengan: membelikan paket internet untuk belajar, menyediakan Handphone (Gawai/ gadget) untuk pembelajaran online, mengarahkan untuk membagi waktu belajar dan bermain, mendampingi saya ketika belajar daring, memberikan vitamin supaya sehat dan selalu mendoakan saya supaya jadi anak yang pandai. Sedangkan peran guru semasa pandemik Covid19 antara lain dengan: menyampaikan materi pelajaran daring dengan jelas dan ringkas, memberikan tugas pembelajaran melalui daring, 
tidak membeda-bedakan murid dalam memberikan nilai, memotivasi agar semangat dalam belajar daring, dan mengarahkan siswa untuk mengerjakan tugas daring dengan baik.

Dengan penjabaran seperti diatas dapat dikatakan bahwa perubahan motivasi belajar siswa semasa pandemik Covid-19 di Sekolah Dasar Islam Assakinah yang disebabkan oleh pengaruh perhatian orang tua dan peran guru mempunyai pengaruh $32,8 \%$ dan yang $67,2 \%$ dapat dipengaruhi oleh faktor lain.

\section{Analisis goodness of fit}

Berdasarkan kriteria uji, Chi-square $\left(\mathrm{x}^{2}\right)$, Probabilitas, GFI, AGFI, CFI, TLI, Relatif Chisquarel CMIN/DF ( $\left.\mathrm{x}^{2} / \mathrm{df}\right)$ dan RMSEA yang sudah dibahas diatas dan nilai Goodness of Fit hasil dari pengolahan Amos for windows, sebagaimana ditampilkan pada gambar di atas, maka dapat disajikan dalam sebuah tabel sebagai berikut.

Tabel 14.

Evaluasi Goodness of Fit

\begin{tabular}{|c|c|c|c|}
\hline $\begin{array}{c}\text { Goodness } \\
\text { of Fit } \\
\text { Index }\end{array}$ & $\begin{array}{c}\text { Cut-of } \\
\text { Value }\end{array}$ & $\begin{array}{c}\text { Hasil } \\
\text { Model }\end{array}$ & Keterangan \\
\hline $\begin{array}{c}\text { Chi-square } \\
\left(\mathrm{X}^{2}\right)\end{array}$ & $\begin{array}{c}\text { Diharapkan } \\
\text { kecil }\end{array}$ & 141,381 & Kurang baik \\
\hline Probabilitas & $>0,05$ & 0,055 & Baik \\
\hline GFI & $\geq 0,90$ & 0,923 & Baik \\
\hline AGFI & $\geq 0,90$ & 0,898 & Marginal \\
\hline CFI & $\geq 0,90$ & 0,981 & Baik \\
\hline TLI & $\geq 0,90$ & 0,978 & Baik \\
\hline CMIN/DF & $\leq 3,00$ & 1,219 & Baik \\
\hline RMSEA & $\leq 0,08$ & 0,034 & Baik \\
\hline
\end{tabular}

Pada Tabel 14 dapat dilihat bahwa nilai cut-of-value dan goodness of fit hasil model, terlihat 6 kriteria yang terpenuhi, 1 marginal dan 1 kurang baik dari 8 kriteria yang dipakai. Kriteria yang terpenuhi adalah Probabilitas, GFI, CFI, TLI, Relatif Chi-square/ CMIN/DF $\left(x^{2} / d f\right)$ dan RMSEA. Sedangakan nilai Chisquare $\left(x^{2}\right)=141,381$ menunjukan model kurang baik, akan tetapi nilai Chi-square $\left(\mathrm{x}^{2}\right)$ sensitif terhadap jumlah sampel. Oleh karena itu perlu kita lihat kriteria fit yang lain yaitu probabilitas, GFI, AGFI, CFI, TLI, Relatif Chisquare/ CMIN/DF ( $\left.x^{2} / \mathrm{df}\right)$ dan RMSEA. Karena sudah 6 kriteria terpenuhi dan 1 yang marginal dari delapan kriteria yang disyaratkan, oleh karena itu model di atas dapat disimpulkan sebagai model yang baik. (Yasa, 2020).

\section{PENUTUP}

\section{Simpulan}

Hasil penelitian yang telah dibahas dan dijelakan diatas, menunjukan kesimpulan yang pertama bahwa perhatian orang tua $\left(X_{1}\right)$ berpengaruh secara positif dan signifikan terhadap motivasi belajar siswa (Y) semasa pandemik Covid-19 di Sekolah Dasar Islam Assakinah Batam. Kesimpulan yang kedua peran guru $\left(X_{2}\right)$ berpengaruh secara positif dan signifikan terhadap motivasi belajar siswa (Y) semasa pandemik Covid-19 di Sekolah Dasar Islam Assakinah Batam.

\section{Saran}

Perhatian orang tua dan perang guru sangat penting dalam proses pembelajaran daring selama pandemik Covid-19, oleh karea itu perhatian orang tua dan peran guru hendaknya lebih ditingkatkan lagi supaya proses pembelajaran bisa berjalan dengan baik dan sesuai harapan.

\section{DAFTAR PUSTAKA}

Alfitriyani, K. N. (2019). The Influence of Learning Motivation and Self Confidence Toward English Learning Achievement of The Second Grade Students of SMA N 1 Srandakan in The Academic Year 2018/2019. English Language Teaching Educational Journal (ELTEJ), 1(1), 1-14. Ambarwati, W. (2018). Influence of Parents Attention, Emotional Intelligence and Learning Motivation to Learning Outcomes. Journal of Education, Teaching and Learning, 3 (1,) 72-81. 
Arikunto, Suharsimi. (2014). Prosedur Penelitian Suatu Pendekatan Praktik. Yogyakarta: Rineka Cipta.

Darmawan, S. (2018). Pengaruh Lingkungan Sekolah, Peran Guru Dan Minat Belajar Siswa Terhadap Motivasi Belajar Penjas Sd Inpres Buttatianang I Makassar. Jurnal Muara Pendidikan, 3 (2), 103-111

Coyne., L. W., Gould, E. R., Grimaldi, M., Wilson, K. G., Baffuto, G., \& Biglan, A. (2020). First Things First: Parent Psychological Flexibilityand SelfCompassion During COVID-19. Journal Behavior Analysis in Practice. https://doi.org/10.1007/s40617-02000435-w

Fijar, N. Y., Muchtar, B., \& Idris. (2019). The Effect of Parental Attention, Home Study Facilities and Learning Motivation on Students Learning Outcome (Research : Social Sciense Subject in District Sungayang High School Tanah Datar Regency). Jurnal Aplikasi IPTEK Indonesia, Open Access, http://bk.ppj.unp.ac.id/index.php/aiptekin/ index

Fitriyani, Y., Fauzi, I., \& Sari, M. (2020). Motivasi Belajar Mahasiswa Pada Pembelajaran Daring Selama Pandemik Covid-19. Jurnal Kependidikan: Jurnal Hasil Penelitian dan Kajian Kepustakaan di Bidang Pendidikan, Pengajaran dan Pembelajaran, 6(2), 165-175. DOI: https://doi.org/10.33394/jk.v6i2.2654

Garbe, A., Ogurlu, U., Logan, N.,\& Cook, P. (2020). COVID-19 and Remote Learning: Experiences of Parents with Children during the Pandemic. American Journal of Qualitative Research, 4(3), 45-65. https://doi.org/10.29333/ajqr/8471

Ghozali, I. (2017). Model Persamaan Struktural Konsep Dan Aplikasi Dengan Program Amos 24 Edisi 7. Semarang: Badan Penerbit UniversitasDiponegoro

Griffith, A. K. (2020). Parental Burnout and Child Maltreatment During the COVID19 Pandemic. Journal of Family Violence https://doi.org/10.1007/s10896-020$\underline{00172-2}$
Haditama, L., Wardi, Y. \& Syamwil. (2018). The Effect of Parents Attention, Learning Discipline and Learning Motivation to Learning Outcomes of Students at the Student Financial Accounting Class. International Conferences on Educational,Social Sciences and Technology, Padang, February 14th 15th, 789-798. DOI: https://doi.org/10.29210/20181115

Handayani, S. (2016). Pengaruh Perhatian Orangtua Dan Minat Belajar Matematika Terhadap Prestasi Belajar Matematika Siswa. Jurnal Formatif 6(2): 141-148.

Helmawati. (2016). Pendidikan Keluarga Teoretis Dan Praktis. Bandung: PT Remaja Rosda Karya.

Kardo, R. \& Yuzarion. (2017). S1kap Guru Terhadap Peserta Didik Dalam Belajar. Jurnal Ilmu Pendıdıkan, 2 (2), 189-195

Mehdipour, Y \& Balaramulu, D. (2013). The Influence of Teacher's Behavior on the Student's Self-Regulation. IOSR Journal of Research \& Method in Education (IOSR-JRME, 1(6), 65-71.

Mansora, N. B. Y., \& Ahmada, A. (2016). The Influence Of Parents Support And Its Relationship With Students Achievement In English Education. International Conference on Education and Regional Development (ICERD). Bandung. Pp 657662. Diunduh 26 Agustus 2020, https://www.academia.edu

Pajarianto, H., Kadir, A., Galugu, N., Sari, P. \& Februant, S. (2020). Study from Home in the Middle of the COVID-19 Pandemic: Analysis of Religiosity, Teacher, and Parents Support Against Academic Stress. Journal Talent Development \& Excellence, 12, (2s), 1791-1807

Pan, S. L., Cui, M.,\& Qian, J. (2020). nformation resource orchestration during the COVID-19 pandemic: A studyof community lockdowns in China. International Journal of Information Management 54. https://doi.org/10.1016/j.ijinfomgt.2020.1 $\underline{02143 .}$.

Prasetyo, A., \& Sukarni. (2021). Pengaruh Perhatian Orang Tua Terhadap Prestasi 
Belajar Pendidikan Agama Islam Siswa Kelas XII di SMKN I Batam. Jurnal MUADDIB: Studi Kependidikan dan Keislaman 11(01), 1-19. http://dx.doi.org/10.24269/muaddib.v1i1. $\underline{2721}$

Prianto, A., \& Putri, T. H. (2017). Pengaruh Ketersediaan Fasilitas Belajar, Dukungan Orang Tua Yang Dirasakan Terhadapmotivasi Dan Prestasi Belajar Siswa SMA PGRI Ngimbang Lamongan. Jurnal Pendidikan Ekonomi, Kewirausahaan, Bisnis, dan Manajemen (JPEKBM), 1(2), 13-38.

Purwanto, A., Asbari, M., Fahlevi, M., Mufid, A., Agistiawati, A., Cahyono, Y.,\& Suryani, P. (2020). Impact of Work From Home (WFH) on Indonesian Teachers Performance During the Covid-19 Pandemic: An Exploratory Study. International Journal of Advanced Science and Technology, 29(5), 6235 6244.

Rashid, M. A. U. H \& SaeedUzZaman. (2018). Effects of Teacher's Behavior on Academic Performance of Students. Conference Paper. diunduh 25 Agustus 2020,

https://www.researchgate.net/publication/ 325248514

Sugiyono. (2017). Metode Penelitian Manajemen, Pendekatan: Kuantitatif, kualitatif, Kombinasi (Mixed Methode), Penelitian Tindakan (Action Research), Penelitian Evaluasi. Bandung: Alfabeta.

Supriyanto, W. \& Iswandiri, R. (2017). Kecenderungan Sivitas Akademika Dalam Memılıh Sumber Referensı Untuk Penyusunan Karya Tulıs Ilmiah D1 Perguruan Tinggi. Jurnal Berkala Ilmu Perpustakaan dan Informasi, 13(1), 7986.

Tambunan, H. (2018). The Dominant Factor of Teacher's Role as A Motivator of Students' Interest and Motivation in Mathematics Achievement. International Education Studies; 11( 4), 114-151.

Tellu, T., Kadir, A., \& Kasim, A. (2017). Effect of Parent's Attention, Self- Concept, and Self-Study on Biology Students'
Achievement at SMA Negeri 2 Sigi Biromaru. Journal Advances in Social Science, Education and Humanities Research, Vol. 174, pp. 342-345. DOI

https://doi.org/10.2991/ice-17.2018.73

Vinorita, D., \& Muhsin. (2018). Pengaruh perhatian orang tua, komunikasi guru, pemberian reward, dan fasilitas belajar terhadap motivasi belajar. Economic Education Analysis Journal, 7( 2), 553567.

Yasa, I. W. C., Wibisono, C., Gulo, E. \& Prasetyo, A. (2020). Determination Compensation, Leadership, And Organizational Culture on Performance Through Employee Work Satisfaction. International Journal of Psychosocial Rehabilitation, 24(07), 8758-8764.

Yurniati, D, Syofyan, E., \& Marwan. (2018). The Effect of Teacher's Role, Learning Motivation and Students' Creativity towardLearning Outcome on Workshop and Entrepreneurship's Subject of XI Grade Studentsin Management Business Vocational School in Padang City. Series:Advances in Economics, Business and Management Research, Proceedings of the 2nd Padang International Conference on Education, Economics, Business and Accounting (PICEEBA-2). Diunduh 25 Agustus 2020, https://www.atlantispress.com/proceedings/piceeba2$\underline{18 / 125907985}$ 